\title{
PELATIHAN DAN PENGIMPLEMENTASIAN ILMU MANAJEMEN PADA DUNIA KERJA SERTA DUNIA INDUSTRI PADA SISWA SISWI SMK LINGGA KENCANA DEPOK
}

\author{
Ardi Bachtiar $^{1}$, Indri Kharisma ${ }^{2}$, Tutri Indraswari ${ }^{3}$, Kartika Sari Dewi ${ }^{4}$, Wuguh Pitono ${ }^{5}$ \\ Dosen Manajemen Fakultas Ekonomi Universitas Pamulang
}

Email: ardiebactiar03@gmail.com, indri.kharisma@gmail.com, indraswari.tri04@gmail.com, kartikascorpio@yahoo.co.id, wuguhpitono@gmail.com

\begin{abstract}
Community Service Program aims to provide understanding and implementation of student management in the world of work and industry so that students and students are able to apply it and apply management knowledge as a leadership or young entrepreneur, students and students become open-minded in managing their financial lives in a way independent and useful for others after they graduate later. The method of activity used was in collaboration with Depok's Lingga Kencana Vocational School, located at Jl. Raya Sawangan No. 47 Depok and provide training and implementation of Management in the world of work and industry so that it can provide the right stock in motivating students of Smk Lingga Kencana Depok who are the successors of the millennial generation in Depok, West Java. After being analyzed, we provide training in the form of materials and practices aimed at developing the ability to increase knowledge about Management Science. The results of the activities showed that before the implementation of PKM, the students of Smk Lingga Kencana did not know more clearly about the application of management knowledge in the world of work and the world of industry, but after the implementation of this PKM activity it was known that students of Smk Lingga Kencana Depok already had provisions and could understand how the application of management knowledge to the world of work and industry when they graduate. PKM activities play a positive role in increasing the knowledge and skills of participants when they become leaders and entrepreneurs.
\end{abstract}

Keywords: PKM, Management Science, World of Work, World of Industry

\begin{abstract}
Abstrak
Kegiatan Pegabdian Kepada Masyarakat ini bertujuan untuk memberikan pemahaman dan pengimplementasian manajemen para siswa pada dunia kerja serta dunia industri sehingga para siswa dan siswi mampu mengaplikasikannya dan menerapkan ilmu manajemen sebagai leadership ataupun enterpreneur muda, para siswa dan siswi menjadi terbuka pemikirannya dalam mengatur kehidupan financial mereka secara mandiri dan bermanfaat untuk orang lain setelah mereka lulus nanti. Metode kegiatan yang digunakan adalah bekerjasama dengan SMK Lingga Kencana Depok, yang beralamat di Jl. Raya Sawangan No. 47 Depok dan memberikan pelatihan serta pengimplementasian Ilmu Manajamen pada dunia kerja serta dunia industri sehingga dapat memberikan bekal yang tepat dalam memotivasi siswa siswi Smk Lingga Kencana Depok yang adalah penerus generasi muda yang milenial di Kota Depok Jawa Barat. Setelah dianalisis maka kami memberikan pelatihan dalam bentuk materi dan praktek yang bertujuan mengembangkan kemampuan untuk meningkatkan pengetahuan mengenai Ilmu Manajemen. Hasil kegiatan menunjukkan bahwa sebelum pelaksanaan PKM, para siswa siswi Smk Lingga Kencana belum mengetahui lebih jelas mengenai penerapan ilmu manajemen dalam dunia kerja serta dunia indutri, namun setelah pelaksaan kegiatan PKM ini diketahui para siswa siswi Smk Lingga Kencana Depok sudah mempunyai bekal dan dapat memahami bagaimana penerapan ilmu manajemen pada dunia kerja serta dunia industri ketika mereka sudah lulus.. Kegiatan PKM berperan positif dalam meningkatkan pengetahuan dan keterampilan peserta saat mereka menjadi leadership dan enterpreneur.
\end{abstract}

Kata Kunci : PKM, Ilmu Manajemen, Dunia Kerja, Dunia Industri 


\section{PENDAHULUAN}

\subsection{Analisis Situasi Permasalahan}

Seiring dengan perkembangan industri di Indonesia yang saat ini sedang berkembang pesat, tuntutan terhadap kemampuan SDM nya pun semakin tinggi, namun hal ini tidak diimbangi dengan pemahaman ilmu manajemen yang baik pula. Khususnya pada SDM dari lulusanlulusan Sekolah Menengah Atas, sehingga hal ini membuat mereka belum siap terjun langsung ke dunia kerja serta dunia industri. Oleh karena itu mereka perlu dibekali dengan berbagai macam problem solving oleh pengabdian kepada masyarakat kali ini, yang tema nya kali ini yaitu tentang bagaimana mengimplementasikan ilmu manajemen dalam dunia kerja serta dunia indutri.

Dari hasil pengamatan dan survei lokasi di SMK Lingga Kencana Depok diketahui terdapat 3 kejuruan yaitu Administrasi Perkantoran, Tata Niaga (pemasaran) dan Perbankan Syariah. Dalam menjalankan kegiatannya para siswa dituntut untuk memahami ilmu dan teori yang berada pada jurusannya masingmasing dan mampu mengimplementasikannya dalam dunia kerja serta dunia industri.

Dengan adanya materi tentang pelatihan dan pengimplementasian ilmu manajemen ini, diharapkan para siswa memiliki kemampuan lebih setelah lulus nanti. Ilmu manajemen ini juga melatih para siswa untuk lebih mandiri dalam menentukan keputusan untuk melanjutkan kependidikan tinggi atau bekerja atau malah berwirausaha.

\subsection{Rumusan Masalah}

Berdasarkan latar belakang masalah yang sudah dipaparkan diatas bahwa dibutuhkan pelatihan dan pengimplementasian ilmu mananjemen pada dunia kerja serta dunia industri, oleh karena itu kami merumuskan masalah dalam pengabdian kepada masyarakat ini yaitu :

a. Bagaimana memberikan pemahaman dan pengimplementasian manajemen para siswa dalam dunia kerja? b. Bagaimana memberikan pemahaman dan pengimplementasian manajemen para siswa dalam dunia industri ?

1.3 Tujuan Pengabdian kepada Masyarakat

a. Untuk memberikan pemahaman dan pengimplementasian manajemen para siswa dalam dunia kerja?

b. Untuk memberikan pemahaman dan pengimplementasian manajemen para siswa dalam dunia Industri ?

\subsection{Manfaat Pengabdian kepada \\ Masyarakat}

a. Secara Teoritis

Pengabdian ini diharapkan dapatkan memberikan sumbangan dalam aspek teoritis (keilmuan) yaitu dapat memberikan pemikiran, pengetahuan dan gambaran yang lebih jelas mengenai faktor-faktor fundamental dan sebagai aplikasi penerapan dalam ilmu manajemen.

b. Secara Praktis

Hasil pengabdian ini diharapkan dapat memberikan gambaran secara nyata bagi siswa siswi SMK Lingga Kencana dalam mengimplementasikan ilmu manajemen dalam dunia kerja serta dunia industri.

\section{TINJAUAN PUSTAKA}

\subsection{Manajemen}

\section{a. Pengertian Manajemen}

Manajemen berasal dari bahasa Latin yaitu dari asal kata manus yang berarti tangan dan agree (melakukan). Kata itu kemudian digabung menjadi managere yang artinya menangani. Managere di terjemahkan dalam bahasa Inggris to manage (kata kerja), management (kata benda) dan manager untuk orang yang melakukannya.

Management diterjemahkan ke bahasa Indonesia menjadi manajemen (pengelolaan).

\section{b. Fungsi Manajemen}

Menurut M Manulang (2004:7) manajemen memiliki fungsi diantaranya sebagai berikut :

1) Forcasting (Perencanaan)

Forcasting (peramalan) adalah kegiatan meramalkan, 
memproyeksikan atau mengadakan taksiran terhadap berbagai kemungkinan yang akan terjadi sebelumnya suatu rencana yang lebih pasti dapat dilakukan. Misalnya, suatu akademi meramalkan jumlah mahasiswa yang akan melamar belajar ke akademi tersebut.

2) Planning (Perencanaan)

Planning (perencanaan) adalah penentuan serangkaian tindakan untuk mencapai suatu hasil yang akan diinginkan.

3) Organizing (Pengorganisasian)

Organizing dimaksud mengelompokkan kegiatan yang diperlukan yakni penetapan susunan organisasi serta tugas dan fungsi-fungsi dari setiap unit yang ada dalam organisasi serta menetapkan kedudukan dan sifat hubungan antara masing-masing untit tersebut.

4) Staffing

Staffing merupakan salah satu fungsi manajemen berupa penyusunan personalia pada suatu organisasi sejak dari merekrut tenaga kerja, pengembangannya sampai dengan usaha agar setiap tenaga memberi daya guna maksimal kepada organisasi.

5) Directing

Directing adalah fungsi manajemen yang berhubungan dengan usaha memberi bimbingan, saran, perintahperintah atau instruksi kepada bawahan dalam melaksanakan tugas masing-masing agar tugas dpat dilaksanakan dengan baik dan benar-benar tertuju pada tujuan yang telah ditetapkan semula.

6) Leading

Leading merupakan salah satu fungsi manajemen dikemukakan oleh Louis A Allen yang dirumuskan sebagai pekerjaan yang dilakukan oleh seorang manajer yang menyebabkan orang lain bertindak seperti mengambil keputusan, mengadakan komunikasi agar ada saling pengertian antara manajer dengan bawahan, memberi semangat, inspirasi dan dorongan kepada bawahan supaya mereka bertindak.

7) Coordinating

Coordinating merupakan salah satu fungsi manajemen untuk melakukan berbagai kegiatan agar tidak terjadi kekacauan, percekcokan, kekosongan kegiatan, dengan jalan menghubungkan, menyatukan dan menyelaraskan pekerjaan bawahan sehingga terdapat kerja sama yang terarah dalam usaha mencapai tujuan organisasi.

8) Motivating

Motivating merupakan salah satu fungsi manajemen berupa pemberian inspirasi, semangat dan dorongan kepada bawahan agar bawahan melakukan kegiatan secara suka rela sesuai apa yang dikehendaki oleh atasan.

9) Controlling

Controlling merupakan penyampaian perkembangan atau hasil kegiatan atau pemberian keterangan mengenai segala hal yangbertalian dengan tugas dan fungsi-fungsi kepad pejabat yang lebih tinggi, baik secara lisan maupun tulisa, sehingga dalam penerimaan laporan dapat memperoleh gambaran bagaimana pelaksanaan tugas orang yang memberi laporan.

\section{c. Unsur Manajemen}

Menurut George Terry (2006:34) manajemen terdiri dari 6 unsur $(6 \mathrm{M})$ yaitu :
1) Manusia (Man), dalam manajemen, faktor manusia adalah yang paling menentukan. Manusia yang membuat tujuan dan manusia pula yang melakukan proses untuk 
mencapai tujuan. Tanpa ada manusia tidak ada proses kerja, sebab pada dasarnya manusia adalah makhluk kerja.

2) Uang (Money), uang merupakan salah satu unsur yang tidak dapat diabaikan. Uang merupakan alat tukar dan alat pengukur nilai. Besar kecilnya hasil kegiatan dapat diukur dari jumlah uang yang beredar dalam perusahaan. Oleh karena tu uang merupakan alat (tools) yang penting untuk mencapai tujuan karena segala sesuatu harus diperhitungkan secara rasional. Hal ini akan berhubungan dengan berapa uang yang harus disediakan untuk membiayai gaji tenaga kerja. Alatalat yang dibutuhkan dan harus dibeli serta beberapa hasil yang akan dicapai dari suatu organisasi.

3) Bahan (Materials), materi terdiri dari bahan setengah jadi (raw material) dan bahan jadi. Dalam dunia usaha untuk mencapai hasil yang lebih baik, selain manusia yang ahli dalam bidangnya jug harus dapat menggunakan bahan atau materi-materi sebagai salah satu sarana. Sebab materi dan manusia tidak dapat dipisahkan, tanpa materi tidak akan tercapai hasil yang dikendaki.

4) Mesin (Machines), dalam kegiatan perusahaan, mesin sangat diperlukan. Penggunaan mesin akan membawa kemudahan atau menghasilkan keuntungan yang lebih besar serta menciptakan efisiensi kerja.

5) Metode (Methods), dalam pelaksanaan kerja diperlukan metode-metode kerja. Suatu tata cara kerja yang baik akan memperlancar jalannya pekerjaan. Sebuah metode dapat dinyatakan sebagai penetapan cara pelaksanaan kerja suatu tugas dengan memberikan berbagai pertimbangan-pertimbangan kepada sasaran, fasilitas-fasilitas yang tersedia dan penggunaan waktu, serta uang dan kegiatan usaha. Perlu diingat meskipun metode baik, sedangkan orang yang melaksanakannya tidak mengerti atau tidak mempunyai pengalaman maka hasilnya tidak akan memuaskan. Dengan demikian, peranan utama dalam manajemen tetap manusianya sendiri.

6) Pasar (Market), memasarkan produk sudah barang tentu sangat penting sebab bila barang yang diproduksi tidak laku, maka proses produksi barang akan berhenti. Artinya, proses kerja tidak akan berlangsung. Oleh sebab itu, penguasaan pasar dalam arti menyebarkan hasil produksi merupakan faktor menentukan dalam perusahaan. Agar pasar dapat dikuasai maka kualitas dan harga barang harus sesuai dengan selera konsumen dan daya beli (kemampuan) konsumen.

\section{MATERI DAN METODE PELAKSANAAN}

\subsection{Kerangka Pemecahan Masalah}

Persetujuan proposal pengabdian kepada masyarakat pada kampus Universitas Pamulang dan SMK Lingga Kencana Jl. Raya Sawangan Kec. Pancoran Mas Depok. Guna membekali para siswa ilmu tentang manajemen serta pelatihan pengimplementasian ilmu manajemen dalam dunia kerja serta dunia industri.

Kegiatan ini meliputi bagaimana penerapan ilmu manajemen sebagai leadership ataupun enterpreuner muda, para siswa dan siswi menjadi terbuka pemikirannya dalam mengatur kehidupan financial mereka secara mandiri dan bermanfaat untuk orang lain.

Persiapan yang dilakukan adalah segala hal yang terkait dengan materi, bahan dan alat sesuai dengan tema secara baik. Hasil persiapan tersebut dimaksudkan agar materi tersampaikan dengan mudah dan dimengerti serta dipahami oleh para 
siswa dan siswi SMK Lingga Kencana Depok.

\subsection{Realisasi Pemecahan Masalah}

Kegiatan pengabdian dilaksanakan dengan realisasi rincian acara pelaksanaan sebagai berikut :

Tabel 3.1

Acara Pelaksanaan Kegiatan Kamis, 29 November 2019

\begin{tabular}{|c|c|c|}
\hline $\begin{array}{l}\text { WAK } \\
\text { TU }\end{array}$ & $\begin{array}{l}\text { URAIAN } \\
\text { KEGIAT } \\
\text { AN }\end{array}$ & $\begin{array}{l}\text { KETERANG } \\
\text { AN }\end{array}$ \\
\hline $\begin{array}{l}13.00 \quad- \\
13.30\end{array}$ & $\begin{array}{l}\text { Registrasi } \\
\text { Peserta }\end{array}$ & Panitia \\
\hline $\begin{array}{l}13.30- \\
13.40\end{array}$ & $\begin{array}{l}\text { Pembukaa } \\
\text { an Acara }\end{array}$ & $\begin{array}{l}\text { Mc : Marto, } \\
\text { S.Pd.I }\end{array}$ \\
\hline $\begin{array}{l}13.40- \\
14.00\end{array}$ & $\begin{array}{l}\text { Pembacaa } \\
\text { n Ayat- } \\
\text { ayat suci } \\
\text { al-Quran }\end{array}$ & $\begin{array}{l}\text { Alisya } \\
\text { Asyaroh }\end{array}$ \\
\hline $\begin{array}{l}14.00- \\
14.30\end{array}$ & $\begin{array}{l}\text { Sambutan } \\
\text { Kepala } \\
\text { SMK } \\
\text { Lingga } \\
\text { Kencana } \\
\text { Depok }\end{array}$ & $\begin{array}{l}\text { Ruslan } \\
\text { Muntaha, S.H }\end{array}$ \\
\hline $\begin{array}{l}14.30- \\
15.00\end{array}$ & $\begin{array}{l}\text { Sambutan } \\
\text { Ketua } \\
\text { Pelaksana }\end{array}$ & $\begin{array}{l}\text { Ardi Bachtiar, } \\
\text { S.E.,M.M }\end{array}$ \\
\hline $\begin{array}{l}15.00- \\
16.00\end{array}$ & $\begin{array}{l}\text { Pengenala } \\
\mathrm{n} \quad \text { Acara } \\
\text { Pelatihan }\end{array}$ & $\begin{array}{l}\text { Ardi Bachtiar, } \\
\text { S.E.,M.M }\end{array}$ \\
\hline $\begin{array}{l}16.00- \\
16.30\end{array}$ & Istirahat & Panitia \\
\hline $\begin{array}{l}16.30- \\
17.00\end{array}$ & Selesai & Panitia \\
\hline
\end{tabular}

Jumat, 30 November 2019

\begin{tabular}{|c|c|c|}
\hline $\begin{array}{l}\text { WAK } \\
\text { TU }\end{array}$ & $\begin{array}{l}\text { URAIAN } \\
\text { KEGIATAN }\end{array}$ & $\begin{array}{l}\text { KETERA } \\
\text { NGAN }\end{array}$ \\
\hline $\begin{array}{l}13.00 \\
- \\
13.15\end{array}$ & Pembukaan & $\begin{array}{l}\text { Mc } \\
\text { Marto,S.Pd. } \\
\text { I }\end{array}$ \\
\hline $\begin{array}{l}13.15 \\
- \\
13.45\end{array}$ & $\begin{array}{l}\text { Pengarahan } \\
\text { ketua } \\
\text { pelaksana }\end{array}$ & $\begin{array}{l}\text { Ardi } \\
\text { Bachtiar, } \\
\text { S.E., M.M. }\end{array}$ \\
\hline $\begin{array}{l}13.45 \\
- \\
14.30\end{array}$ & $\begin{array}{l}\text { Materi I : } \\
\text { Peranan dan } \\
\text { Pengimpleme } \\
\text { ntasian pada } \\
\text { dunia industri }\end{array}$ & $\begin{array}{l}\text { Wuguh } \\
\text { Pitono, } \\
\text { S.T., M.M. }\end{array}$ \\
\hline
\end{tabular}

\begin{tabular}{|c|c|c|}
\hline $\begin{array}{l}14.30 \\
- \\
15.00\end{array}$ & $\begin{array}{l}\text { Materi II : } \\
\text { Peranan dan } \\
\text { Pengimpleme } \\
\text { ntasian pada } \\
\text { dunia kerja }\end{array}$ & $\begin{array}{l}\text { Tutri } \\
\text { Indraswari, } \\
\text { S.E., M.M. }\end{array}$ \\
\hline $\begin{array}{l}15.00 \\
- \\
15.20\end{array}$ & $\begin{array}{ll}\text { Sesi } & \text { tanya } \\
\text { jawab } & \end{array}$ & Panitia \\
\hline $\begin{array}{l}15.20 \\
- \\
15.30\end{array}$ & Break & $\begin{array}{l}\text { Seluruh } \\
\text { Peserta }\end{array}$ \\
\hline $\begin{array}{l}15.30 \\
- \\
15.40\end{array}$ & $\begin{array}{l}\text { Kesan dan } \\
\text { Pesan peserta }\end{array}$ & $\begin{array}{l}\text { Indri } \\
\text { Kharisma, } \\
\text { S.E.,M.M. }\end{array}$ \\
\hline $\begin{array}{l}15.40 \\
- \\
15.50\end{array}$ & $\begin{array}{l}\text { Penyerahan } \\
\text { souvenir } \\
\text { kepada SMK } \\
\text { Lingga } \\
\text { Kencana } \\
\text { Depok }\end{array}$ & Panitia \\
\hline $\begin{array}{l}15.50 \\
- \\
16.00\end{array}$ & $\begin{array}{l}\text { Penyerahan } \\
\text { souvenir } \\
\text { kepada siswa } \\
\text { siswi SMK } \\
\text { Lingga } \\
\text { Kencana } \\
\text { Depok }\end{array}$ & Panitia \\
\hline $\begin{array}{l}16.00 \\
- \\
16.30\end{array}$ & Foto bersama & $\begin{array}{l}\text { Panitia dan } \\
\text { Peserta }\end{array}$ \\
\hline $\begin{array}{l}16.30 \\
- \\
16.40 \\
\end{array}$ & $\begin{array}{l}\text { Kultum dan } \\
\text { Doa penutup }\end{array}$ & $\begin{array}{l}\text { Indri } \\
\text { Kharisma, } \\
\text { S.E., M.M. }\end{array}$ \\
\hline
\end{tabular}

\subsection{Khalayak Sasaran}

Sasaran Pengabdian kepada Masyarakat kali ini yaitu siswa siswi SMK Lingga Kencana Depok kelas XII jurusan Perbankan Syariah, terdiri dari 35 orang siswa-siswi.

\subsection{Tempat dan Waktu Pengabdian}

a. Tempat Pengabdian

Pelaksanaan kegiatan pengabdian kepada masyarakat di SMK Lingga Kencana Depok tepatnya di Jln Raya Sawangan Depok No.47 Kec. Pancoran Mas Depok 16434.

b. Waktu Pengabdian

Pengabdian kepada Masyarakat dilaksanakan pada Hari Jumat dan 
Sabtu tanggal 29-30 November 2019, dilaksanakan dari pukul 13.00-15.00.

\subsection{Metode Kegiatan}

Metode kegiatan yang digunakan adalah dengan cara survey dan kami mengunjungi SMK Lingga kencana Jln. Raya Sawangan Kec. Pancoran Mas Depok, dan memberikan pelatihan disana.

\section{HASIL DAN PEMBAHASAN}

\subsection{Gambaran Umum}

Tempat pelaksanaan kegiatan pengabdian masyarakat oleh dosen-dosen dari Universitas Pamulang adalah sebuah sekolah menengah kejuruan dengan nama SMK Lingga Kencana yang beralamatkan di Jl. Raya Sawangan Kec. Pancoran Mas Depok no 47. Di sekolah menengah kejuruan ini terdapat tiga kejuruan yaitu Pemasaran, Perbankan Syariah dan Administrasi Perkantoran. Dalam kegiatan pelatihan dan pengimplementasian ilmu manajemen pada sekolah ini, para pemateri menjelaskan dan memberikan gambaran secara singkat bagaimana ilmu manajemen diterapkan secara langsung di dalam perusahaan.

\subsection{Hasil dan Pembahasan \\ 4.2.1 Fungsi Manajemen Dalam Dunia Industri}

Manajemen Industri merupakan kemampuan suatu manajemen industri dalam upaya pengembangan industri, untuk mencapai tujuan yang diharapkan yang meliputi planning, organizing, actuating dan controlling. Aktivitas ekonomi dalam dunia industri merupakan pengolahan bahan mentah, bahan baku, barang setengah jadi menjadi barang atau produk yang memiliki nilai ekonomi yang tinggi.

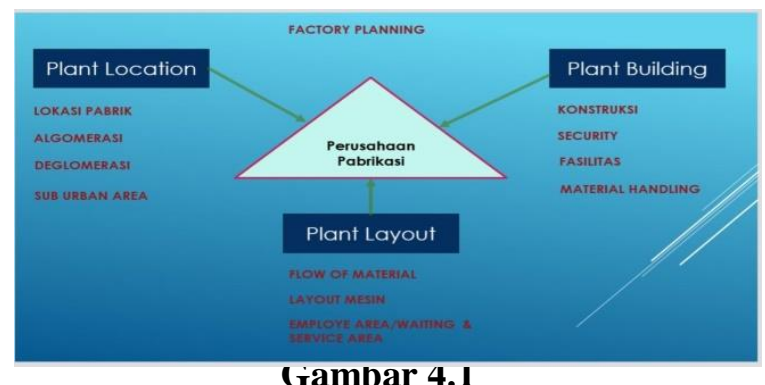

Dengan kata lain, manajemen industri merupakan kemampuan manajemen suatu industri dalam upaya pengembangan industri dengan prinsip Planning hingga Controlling, pemenuhan fungsi manajerial untuk mencapai tujuan usaha, tingkatan manajemen yang didukung keterampilan yang dibutuhkan untuk menggerakkan sumber daya manusia (SDM) hingga pasar.

A. Planning

\section{Lokasi}

Lokasi industri harus di rencanakan dengan baik apakah lokasi akan di bangun di area Kawasan industri atau di tempat lain dengan berbagai konsekuensi yang harus di penuhi sesuai peraturan.

2. Bagunan atau Gedung

Banguan atau gedung juga harus di buat dengan perencanaan yang baik dari konstruksi harus di buat sesuai peruntukannya. Keamanan baik dari struktur bangunan maupun akses manusia harus di rancang sejak awal sehingga pada saat fisik banguan sudah jadi tidak ada kesalahan yeng mneyebabkan bangunan harus di bongkar yang akan memakan waktu dan biaya.

3. Fasilitas

Fasilitas penting tujuannya untuk memberikan kenyaman bagi pekerja agar mampu memberikan pelyayan yang optimal untuk kepusan pelanggan. Fasilitas juga harus di rencanakan dari awal seperti ruang tunggu yang aman bagi tamu pelanggan, air conditioner atau Ac, ruang khusus bagi perokok dll.

4. Lay out pabrik

Layout pabrik ini penting untuk memudahkan proses dalam aktivitas industry seperti jalur material (flow material) ini penting dari mana material datang kemudian di simpan atau di proses sehingga pemakaian materialnya bisa fifo. Layout mesin, employe area dan lainnya.

B. Organizing

Agar perencanaan dapat di jalankan dengan baik dibutuhkan juga manajemen sumberdaya manusia yang baik meliputi:

1. Struktur Organisasi

Struktur organisasi ini penting untuk dibuat agar agar setiap bagian memiliki tugas, wewenang serta tanggung jawab yang jelas dalam tugasnya. 
2. Kompetensi karyawan.

Komptensi karywan ini juga harus di jabarkan dengan kriteria yang jelas sesuai dengan fungsi dan tugasnya.

3. Jumlah kebutuhan

Kebutuhan karyawan juga harus di hitung dengan cermat sesuai dengan beban kerja yang akan di emban sehingga tidak terjadi kelebihan atau kekeurangan tenaga kerja dalam menjalankan tugas-tugas yang sudah ditetapkan.

4. Kompensasi

Setiap orang yang bekerja agar terjaga kinerjanya juga harus di berikan kompensasi yang sesuai untuk menghargai jerih payah yang sudah dilakukan untuk mencapai sasaran organisasi.

C. Actuating

Actuating adalah tindakan manjemen untuk menggerakkan semua orang-orang yang terlibat dalam organisasi agar mau menjalankan tujuan orgasisaaBagaimana menggerakan orang-orang yang terlibat dalam organisasi agar mau melakukan apa yang menjadi tujuan organisasi/ perusahaan.

D. Controling

Dengan kata lain, manajemen industri merupakan kemampuan manajemen suatu industri dalam upaya pengembangan industri dengan prinsip Planning hingga Controlling, pemenuhan fungsi manajerial untuk mencapai tujuan usaha, tingkatan manajemen yang didukung keterampilan yang dibutuhkan untuk menggerakkan sumber daya manusia (SDM) hingga pasar.

\subsubsection{Fungsi Manajemen dalam perusahaan Jasa} 4.2.2.1 Gambaran Perusahaan Jasa

Jasa atau pelayanan didefinisikan sebagai kegiatan ekonomi yang menghasilkan waktu, tempat, bentuk dan kegunaan psikologis. Selain itu jasa juga merupakan struktur komprehensif, bukan tunggal dan secara konsisten digunakan dalam berbagai kegiatan bidang usaha yang menggunakan jasa tentunya.Sehingga sistem pelayanan organisasi atau perusahaan pengguna jasa dapat digambarkan sebagai berikut ini :

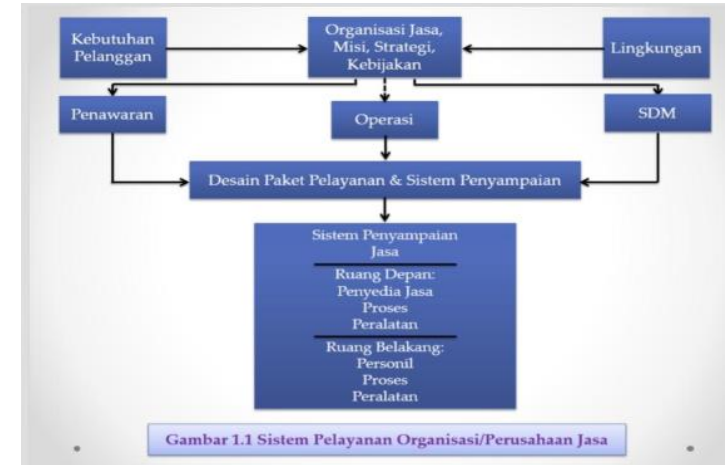

Gambar 4.2

Dalam alur gambar tersebut, menjelaskan pentingnya misi atau tujuan perusahaan pengguna jasa dengan pelaksanaan sebagai berikut :

1. Memastikan adanya satuan kegiatan tujuan dalam organisasi atau perusahaan pengguna jasa

2. Menjadi landasan atau standar dalam mengalokasikan sumber daya organisasi

3. Menciptkan nada dan iklim yang sama

4. Sebagai acuan bagi setiap individu dalam memahami tujuan dan arah organisasi

5. Memfasilitasi tujuan-tujuan organisasi ke arah struktur kerja termasuk penugasan kerja kepada bagian-bagian yang bertanggung jawab dalam organisasi

6. Menjelaskan tujuan-tujuan organisasi dan mengarahkannya dalam tujuan yang sesuai dengan sasaran kegiatan

\subsubsection{Misi perusahaan}

Misi dalam perusahaan juga mencakup :

1. Segmen pasar yang mencakup identifikasi karakterisktik umum pasar berserta kebutuhan-kebutuhan yang ada didalamnya.

2. Konsep Jasa yang mencakup upayaupaya untuk menanamkan dalam pikiran dalam semua bagian di organisasi akan kualitas dan kuantitas yang diberikan.

3. Pengembangan strategi organisasi serta berbagai inovasi yang ada di dalamnya.

4. Sistem penyajian dan pelayanan jasa harus dibangun dengan memperjelas perang masing-masing karyawan yang 
sesuai dengan teknologi yang ada saat ini.

\subsubsection{Hasil Kegiatan diharapkan :}

1. Para siswa diharapkan memiliki sedikit gambaran bagaimana dunia kerja sebenarnya, baik di industri maupun perusahaan jasa.

2. Para siswa mengerti bagaimana penerapan dari fungsi-fungsi manajemen, sehingga selanjutnya sebagai calon perkerja mereka mampu mempersiapkan dan menyesuaikan diri kedepannya.

3. Para siswa dan para pemateri saling bertukar wawasan dan cara pandang bagaimana menyingkapi fenomenafenomena perkembangan ilmu manajemen didalam dunia kerja maupun dunia usaha.

4. Dengan adanya pelatihan dan pengimplementasian ilmu manajemen ini, diharapkan para siswa mampu membekali diri dengan ilmu pengetahuan yang ada sehingga para siswa sebagai calon perkerja mampu memberikan keahlian, keterampilan dan berbagai kemampuan lainnya sesuai dengan kebutuhan berbagai perusahaan, baik industri maupun perusahaan jasa sebagai pembuka lapangan kerja.

5. Memberikan pemahaman kepada siswa pentingnya manjeman dalam indsutri yang meliputi perencanaan, pengorganisasian, dan control.

6. Para siswa dapat mengenal lebih dini gambaran kebutuhan kompetensi yang harus di miliki sebelum terjun kedunia industri.

\section{KESIMPULAN DAN SARAN}

Pelaksanaan kegiatan pengabdian kepada masyarakat oleh Lembaga Penelitian dan Pengabdian Masyarakat (LPPM) Universitas Pamulang yang dilakukan oleh dosen-dosen program studi manajemen telah berjalan dengan lancar dan mendapat sambutan hangat dari tempat pelaksanaan kegiatan ini yaitu SMK Lingga Kencana Jl. Raya Sawangan Kec. Pancoran Mas Depok.
Harapan kami dengan pengabdian ini dapat menambah pemahaman dan wawasan tentang ilmu manajemen dalam dunia kerja serta dunia industri. Materi yang kami berikan yaitu pembelajaran dan praktek dalam bidang manajemen khususnya manajemen sumber daya manusia yang baik sekaligus bahan kajian dan masukan bagi para siswa-siswi tersebut untuk dapat mengimplementasikannya dalam kehidupan sehari-hari, sehingga dapat membantu dan meningkatkan tingkat keilmuan dan kepribadian yang sehat dan bermanfat dalam kehidupan mereka pada masa yang akan datang.

Dalam laporan kegiatan ini mungkin banyak kekurangan yang ada, untuk itu kami berharap masukan dan kritikan dalam rangka perbaikan untuk kegiatan-kegiatan pengabdian masyarakat di masa yang akan datang. Semoga kegiatan pengabdian masyarakat ini dapat bermanfaat bagi masyarakat sekitar Universitas Pamulang.

Akhirnya, kami mengucapkan terima kasih kepada seluruh pihak yang telah mendukung kegiatan yang kami laksanakan dan kami mohon maaf apabila dalam laporan ini banyak ditemukan kekurangan.

\section{DAFTAR PUSTAKA}

Achmad S Rucky. 2006. Manfaat Kompetensi

Aedi, Nur dan Rosalin. Elin. 2011. Manajemen Pendidikan: Kerjasama Sekolah dan Industri

Ambar, Teguh Sulistiyani Rosidah. 2009. Manajemen Sumber Daya Manusia Konsep Teori dan Pengembangan dalam Konteks Organisasi Publik. Yogyakarta : Graha Ilmu

Pasaribu, V. L. D., Agrasadya, A., Shabrina, N., \& Krisnaldy, K. (2020). MENJADI

ENTERPRENEUR MUDA YANG

MEMILIKI JIWA LEADERSHIP UNTUK

MENGHADAPI MASA DEPAN. Abdi

Laksana, 1(1)

Pasaribu, V. L. D., Elburdah, R. P., Sudarso, E., \& Fauziah, G. (2020). PENGGUNAAN MANAJEMEN WAKTU TERHADAP PENINGKATAN PRESTASI BELAJAR DI SMP ARAISIYAH. Jurnal ABDIMAS, 1(1) 
Pasaribu, V. L. D., Susanti, F., \& Hartuti, E. T. K. (2019). MEMOTIVASI SISWA DAN SISWI SMK LETRIS INDONESIA DI DALAM MENENTUKAN PILIHAN UNTUK MELANJUTKAN PENDIDIKAN ATAU BEKERJA SETELAH LULUS SEKOLAH. Jurnal Pengabdian Dharma Laksana, 1(2), 161-172.

Pasaribu, V. L. D., Oktrima, B., Prabowo, B., Arianto, N., \& Haryoko, U. B. (2020). PROGAM PENDAMPINGAN DAN

PENYELENGGARAAN PENDIDIKAN ANAK PADA USIA DINI TERHADAP PRESTASI BELAJAR DILINGKUNGAN RT 020 RW 009. KEL GIRI PENI. KEC WATES.

YOGYAKARTA. JURNAL LOKABMAS KREATIF, 1(1), 71-75.

Pasaribu, V. L. D., Sulaiman, S., Sutiman, S., Thaharudin, T., \& Purnomo, B. Y. (2020). PENGENALAN LETAK POSYANDU TERDEKAT DIKELURAHAN PISANGAN DENGAN MANAJEMEN PEMASARAN REVOLUSI 4.0 UNTUK MENINGKATKAN PENGETAHUAN MASYARAKAT LETAK DAN FUNGSI POSYANDU TERDEKAT PADA KELURAHAN PISANGAN. DEDIKASI PKM, l(1), 105-110.

Pasaribu, V. L. D., \& Krisnaldy, K. (2019). Manajemen Risiko dan Asuransi.

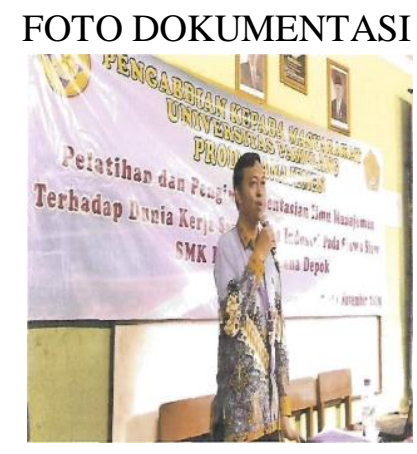

Foto 1. Pembukaan yang dipinipin oleh Ketua PKM, Bapak Ardi BachtiarS.E.,M.M.

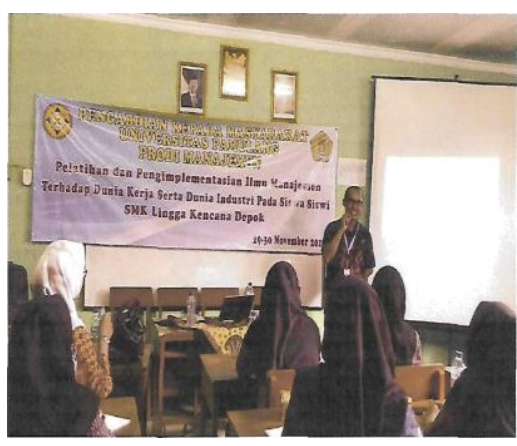

Foto 3. Materi pelatihan 1 yang dibawakan oleh Rapak Wuguh Pitono, S.T.,M.M

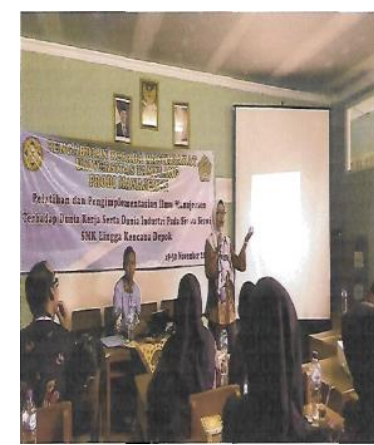

Foto 4. Materi pelatihari2 yang dibawakan oleh Ibu Tqtri Indaswari, S.E.,M.M.

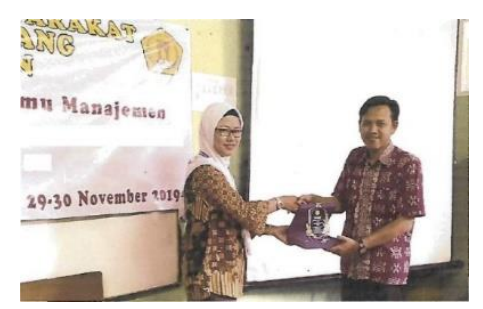

Foto 6. Pemberian Plakat

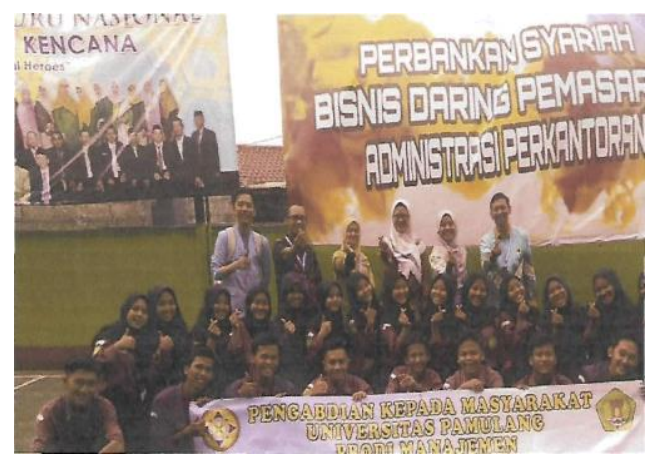

Foto 7. Foto bersama Dosen, mahasiswa dan siswa-siswi Smk Lingga Kencana Depok 